\title{
Cyclooxygenase-2 polymorphisms and the risk of gastric cancer in various degrees of relationship in the Chinese Han population
}

\author{
YUCHUN LI ${ }^{1,2}$, LIPING DAI ${ }^{1,2}$, JIANZHONG ZHANG $^{3}$, PENG WANG $^{1,2}$,

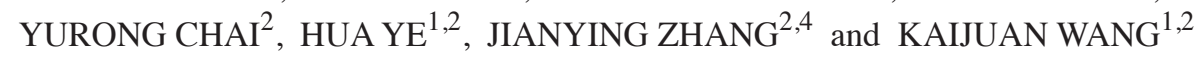 \\ ${ }^{1}$ Department of Epidemiology, College of Public Health, Zhengzhou 450001; ${ }^{2}$ Henan Key Laboratory of Tumor Epidemiology, \\ Zhengzhou University, Zhengzhou, Henan 450052; ${ }^{3}$ Institute for Communicable Disease Control and Prevention, \\ Chinese Center for Disease Control and Prevention, Beijing 102206, P.R. China; \\ ${ }^{4}$ Department of Biological Sciences, University of Texas 79968, El Paso, TX, USA
}

Received May 3, 2011; Accepted September 8, 2011

DOI: $10.3892 / \mathrm{ol} .2011 .426$

\begin{abstract}
A number of studies have shown that cyclooxygenase-2 (COX-2) gene polymorphisms were associated with gastric cancer. However, the results from different research groups have not been consistent. The present study aimed to investigate the association between polymorphisms of the cyclooxygenase-2 promoter region $(-1195 \mathrm{G}>\mathrm{A},-765 \mathrm{G}>\mathrm{C})$ and gastric cancer patients with various degrees of relationship in the Chinese Han population. $C O X-2-1195 \mathrm{G}>\mathrm{A}$ and $C O X-2-765 \mathrm{G}>\mathrm{C}$ polymorphisms in 296 gastric cancer patients and 319 control family members were genotyped using polymerase chain reaction-restriction fragment length polymorphism. An increased risk of gastric cancer was observed in subjects with the $C O X-2-1195 \mathrm{AA}$ genotype $(\mathrm{OR}=2.03$; $95 \% \mathrm{CI}, 1.27-3.22)$, and the association strength decreased as the degree of relationship decreased. Stratification analysis revealed that the OR value of $C O X-2-1195 \mathrm{AA}$ genotype and A carriers exhibited synergy with Helicobacter pylori (H. pylori) infection (AA genotype: OR=2.96; 95\% CI, 1.57 5.58; A carriers: $\mathrm{OR}=2.04 ; 95 \% \mathrm{CI}, 1.18-3.52)$. No significant difference was found in each genotype of $C O X-2-765 \mathrm{G}>\mathrm{C}$ between gastric cancer patients and control family members, as well as gastric cancer patients with various degrees of relationship. Our study demonstrated that the polymorphism of $C O X-2-1195 \mathrm{AA}$ genotype may be a risk factor for gastric cancer patients with various degrees of relationship among the Chinese Han population. H. pylori infection therefore may enhance the risk of gastric cancer in individuals with the COX-2-1195 AA genotype.
\end{abstract}

Correspondence to: Dr Kaijuan Wang and Dr Jianying Zhang, Department of Epidemiology, College of Public Health, Zhengzhou University, No. 100 Science Ave, Zhengzhou, Henan 450001, P.R. China

E-mail: kjwang@163.com; jianyingzhang@hotmail.com

Key words: cyclooxygenase-2, polymorphism, relative degree, gastric cancer

\section{Introduction}

Gastric cancer occurs with a variable geographic distribution worldwide, and the incidence is high in China (1). Helicobacter pylori (H. pylori) infection is an established risk factor in gastric cancer, triggering chronic inflammation of the stomach and leading to stepwise development of the malignancy $(2,3)$. However, a number of previous studies have demonstrated that $H$. pylori is involved in gastric cancer tumorigenesis in a small proportion of individuals infected with the organism, indicating that individual genetic susceptibility may also play a critical role in gastric cancer (4). Subsequent studies further indicated that single nucleotide polymorphism (SNP) may have an effect on gastric tumorigenesis (5). Determinants of the host response to $H$. pylori infection continue to focus on polymorphisms in genes related to innate and acquired immune responses, including $T L R-4$, NOD2 and COX-2 (5-7).

Cyclooxygenase-2 (COX-2) is known as an inducible enzyme that catalyzes conversion of arachidonic acid to prostaglandins in response to various inflammatory stimuli (8). Progression from initial gastric lesions to gastric cancer has been correlated with $C O X-2$ over-expression, providing evidence that its activity may be involved in the onset of gastric carcinogenesis (9). Previous studies demonstrated that $C O X-2$ is also associated with proliferation and apoptosis markers and that it is an independent prognostic factor in gastric cancer (10). At present, 2 polymorphisms in $C O X-2$ have been reported, which are $\mathrm{G}>\mathrm{A}$ and $\mathrm{G}>\mathrm{C}$ base transitions, at positions -1195(rs689466) and -765(rs20417) base pairs (bp) from the transcriptional start site. The promoter region polymorphic variant of $-1195 \mathrm{G}>\mathrm{A}$ and $-765 \mathrm{G}>\mathrm{C}$ has been demonstrated to have a functional effect on $C O X-2$ transcription $(11,12)$, which may cause gastric cancer. Although a number of studies have been carried out to examine the manner in which the two SNPs increase the risk of developing gastric cancer, the results from various groups have not been consistent (13-15).

In the current literature, few studies have examined the role of $C O X-2$ polymorphisms in gastric cancer using gastric cancer case and control family members from the Chinese 
Han population. The current study was performed to evaluate the manner in which the $C O X-2$ polymorphisms and $H$. pylori infection synergistically increased the risk of gastric cancer patients with various degrees of relationship in the Chinese Han population.

\section{Materials and methods}

Study population. A total of 296 subjects from 90 gastric cancer case families, and 319 subjects from 90 control families were included. The individuals in this study were selected from four villages of two counties in the Henan Province of China. Samples were obtained through cluster sampling in this highly cancer-prevalent area following a previous cancer screening. The gastric cancer patient samples were collected from these four villages between August 2003 and March 2007, including samples obtained from patients who had suffered from non-cardiac adenocarcinoma of the stomach during the five years prior to the screening. The patients were histopathologically diagnosed, and were considered as the probands. Their first- and second-degree relatives were further investigated. The control families were selected to correspond to the number of case family members and the age of the probands $( \pm 5$ years), gender and address. Controls were healthy community-based individuals without any similar digestive diseases and had no marital ties with the case family. Subjects in this study provided informed consent prior to participating in the study, and the private data were kept as coded data.

DNA extraction. Blood samples were collected from the subjects and DNA was extracted using the salting-out procedure and stored in a $-80^{\circ} \mathrm{C}$ freezer for subsequent studies.

Genotyping analysis. The COX-2-1195G $>\mathrm{A}$ and $-765 \mathrm{G}>\mathrm{C}$ polymorphisms were genotyped using polymerase chain reaction-restriction fragment length polymorphism. Primers were designed and synthesized by Beijing SBS Genetech Co. Ltd. The sequences were as follows: $C O X-2-1195 \mathrm{G}>\mathrm{A}$ : 5'-CCCTGAGCACTACCCATGAT-3' (forward) and 5'-GCC CTTCATAGGAGATACTGG-3' (reverse). COX-2-765G>C: 5'-TATTATGAGGAGAATTTACCTTTCGC-3' (forward) and 5'-GCTAAGTTGCTTTCAACAGAAGAAAT-3' (reverse). Thermo cycling conditions of PCR were: $C O X-2-1195 \mathrm{G}>\mathrm{A}$ : $95^{\circ} \mathrm{C}$ for $5 \mathrm{~min}, 35$ cycles of $95^{\circ} \mathrm{C}$ for $30 \mathrm{sec}, 54^{\circ} \mathrm{C}$ for $40 \mathrm{sec}$, $72{ }^{\circ} \mathrm{C}$ for $45 \mathrm{sec}$ and finally $72^{\circ} \mathrm{C}$ for $10 \mathrm{~min}$; $\mathrm{COX}-2-765 \mathrm{G}>\mathrm{C}$ : $95^{\circ} \mathrm{C}$ for $5 \mathrm{~min}, 35$ cycles of $95^{\circ} \mathrm{C} \mathrm{s}$ for $30 \mathrm{sec}, 55.5^{\circ} \mathrm{C}$ for $40 \mathrm{sec}, 72^{\circ} \mathrm{C}$ for $45 \mathrm{sec}$ and finally $72^{\circ} \mathrm{C}$ for $10 \mathrm{~min}$. The PCR products were digested with restriction enzymes $P v u \mathrm{II}$ (Takara Biotechnology Co., Ltd.) at $37^{\circ} \mathrm{C}$ overnight for analysis of $C O X-2-1195 \mathrm{G}>\mathrm{A}$ and with HhaI (Takara Biotechnology Co., Ltd.) for $-765 \mathrm{G}>\mathrm{C}$. The digested products were separated using 3\% agarose gel electrophoresis, stained with ethidium bromide and visualized under ultraviolet light. Subsequently, an altered pattern of bands was observed: a single band of 273 bp indicated that $C O X-2-1195 \mathrm{~A} / \mathrm{A}$ was not digested; three bands of 273, 220 and 53 bp indicated that G/A was only partially digested; two bands of 220 and 53 bp indicated that $\mathrm{G} / \mathrm{G}$ was completely digested (Fig. 1). Analogically, COX-2$765 \mathrm{C} / \mathrm{C}$ appeared as a single band of $100 \mathrm{bp}$; G/C, three bands

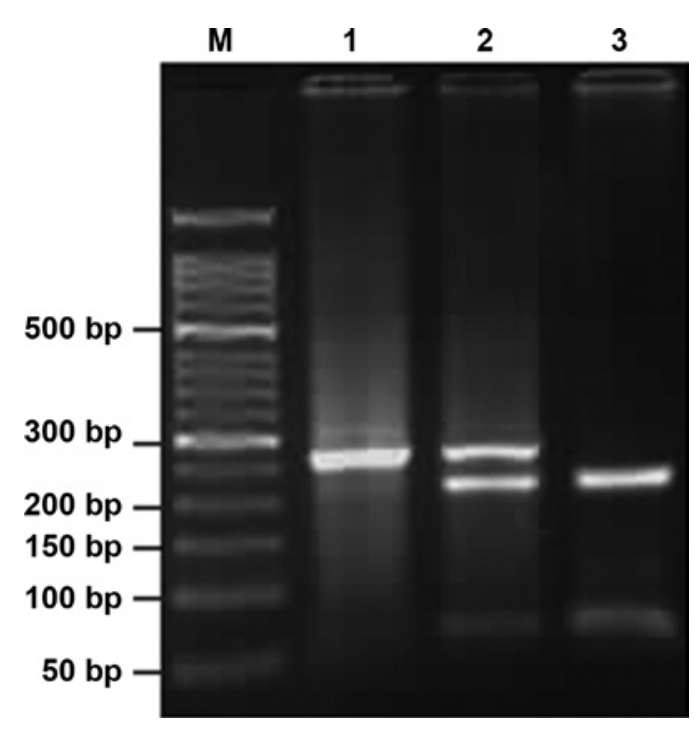

Figure 1. Three genotypes of the $C O X-2-1195$ gene. The results indicated that three genotypes exist in the $C O X-2-1195$ gene following digestion with the restriction enzyme PvuII. (M) Marker; (1) a single band of 273 bp that represented the A/A genotype; (2) three bands of 273, 220 and 53 bp that represented the G/A genotype, and (3) two bands of 220 and 53bp that represented the $\mathrm{G} / \mathrm{G}$ genotype.

of 100,75 and $25 \mathrm{bp}$, and G/G, two bands of 75 and $25 \mathrm{bp}$ (Fig. 2). The 25-bp fragment was not distinguishable from the primer-dimer band in the agarose gel. Each type of PCR product was sequenced to ascertain the genotype. Finally, $10 \%$ of the specimens were genotyped in duplicate using the same assay and the results were $100 \%$ concordant.

H. pylori status analysis. The $H$. pylori immunoglobulin G antibody was determined on the serum specimens of all case and control family members using ELISA. The relevant reagents were provided by the National Institute for Communicable Disease Control and Prevention of the Chinese Center for Disease Control and Prevention.

Statistical analysis. The Hardy-Weinberg equilibrium equation was used to determine whether the proportion of each genotype obtained was in agreement with the expected values as calculated from allele frequencies. The Chi-square test was used to examine the differences in demographic variables. Mean ages of case and control family members were compared using the t-test. Unconditional logistic regression analysis was used to estimate the odds ratio (OR) and its $95 \%$ confidence interval (CI) as a measure of the association between the genotype carrier and risk of gastric cancer. The interaction between $H$. pylori infection and polymorphisms of $C O X-2$ was analyzed using stratification analysis. P-values were two-sided, and $\mathrm{P}<0.05$ was considered as statistically significant. Data analysis was performed by Statistical Product and Service Solutions software (Version 15.0, SPSS, Inc., Chicago, IL, USA) unless otherwise specified. 


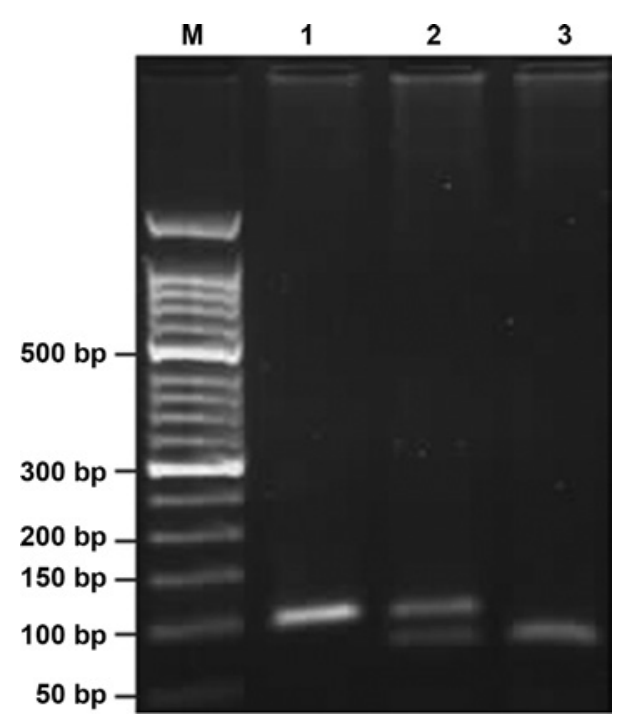

Figure 2. Three genotypes of the COX-2-765 gene. The results indicated that three genotypes exist in the $C O X-2-765$ gene following digestion with restriction enzymes HhaI. (M) Marker, (1) a single band of $100 \mathrm{bp}$ that represented the $\mathrm{C} / \mathrm{C}$ genotype, (2) three bands of 100,75 , and $25 \mathrm{bp}$ that represented the G/C genotype, (3) two bands of 75 and 25 bp represented the $\mathrm{G} / \mathrm{G}$ genotype. The 25-bp fragment was not distinguishable from the primerdimer band in the agarose gel.

\section{Results}

Demographic characteristics. The demographic distribution of case family members and healthy controls is shown in Table I. The mean age of the gastric cancer case families was $44.0 \pm 16.6$ years [mean \pm standard deviation (SD)] and the controls was $44.3 \pm 15.9$ years (mean $\pm \mathrm{SD}, \mathrm{P}=0.81$ ), indicating that there was no difference between the two groups. Males comprised $42.9 \%$ of case family members compared with $43.6 \%$ among controls $(\mathrm{P}=0.87)$. Regarding $H$. pylori infection, there was a significant difference between the case family groups and the controls $(72.3 \%$ versus $62.7 \%$; $\mathrm{P}=0.01)$. With regard to familial history of gastric cancer, case groups exhibited a higher frequeuncy than the controls (19.6\% versus $5.3 \% ; \mathrm{P}<0.01)$.

Genotype frequencies and gastric cancer risk. The genotype distribution and allele frequencies of $C O X-2$ polymorphisms in gastric cancer case and control families are shown in Table II. The genotype distribution of $C O X-2-1195 \mathrm{G}>\mathrm{A}$ and $-765 \mathrm{G}>\mathrm{C}$ in the case and control family members did not significantly deviate from the expected Hardy-Weinberg equilibrium $(\mathrm{P}>0.05)$. For $C O X-2-1195 \mathrm{G}>\mathrm{A}$, the frequencies of GG, GA and AA genotypes were 17.9, 49 and $33.1 \%$ in the case family group and 25.1, 52.0 and $22.9 \%$ in the control group, respectively. Compared with the frequency of the GG genotype, an association was found between the COX-2-1195AA genotype and the risk of gastric cancer (AA genotype: $\mathrm{OR}=2.03 ; 95 \% \mathrm{CI}, 1.27-3.22$ ). A statistical difference was observed between the A carrier and A allele frequencies among the case and control family members (A carriers: $\mathrm{OR}=1.55 ; 95 \% \mathrm{CI}, 1.02-2.28 ;$ A allele: $\mathrm{OR}=$ $1.42 ; 95 \% \mathrm{CI}, 1.09-1.81)$. With regard to $C O X-2-765 \mathrm{G}>\mathrm{C}$, the frequencies of $\mathrm{GG}, \mathrm{GC}$ and $\mathrm{CC}$ genotypes in the case
Table I. Selected characteristic distribution in case and control family group.

\begin{tabular}{lccc}
\hline Variables & $\begin{array}{c}\text { Case family } \\
\text { group (\%) } \\
(\mathrm{n}=296)\end{array}$ & $\begin{array}{c}\text { Control family } \\
\text { group (\%) } \\
(\mathrm{n}=319)\end{array}$ & P-value \\
\hline Mean age (SD) & $44.0(16.6)$ & $44.3(15.9)$ & 0.81 \\
Sex & & & \\
$\quad$ Male & $127(42.9)$ & $139(43.6)$ & 0.87 \\
Female & $169(57.1)$ & $180(56.4)$ & \\
H.pylori & & & \\
Yes & $214(72.3)$ & $200(62.7)$ & $0.01^{\mathrm{a}}$ \\
No & $82(27.7)$ & $119(37.3)$ & \\
Family carcinomas & & & \\
Yes & $58(19.6)$ & $17(5.3)$ & $<0.01^{\mathrm{a}}$ \\
No & $238(80.4)$ & $302(94.7)$ & \\
\hline
\end{tabular}

P, P-value; SD, standard deviation. H. pylori, helicobacter pylori.

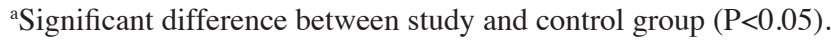

and control family group were 81.4, 17.9 and $0.7 \%$, and $86.2,13.5$ and $0.3 \%$, respectively. Due to the low occurrence $(<1 \%)$ of the $\mathrm{CC}$ genotype, heterozygous and homozygous variants were combined for the analysis (C carriers: $\mathrm{G} / \mathrm{C}$ $+\mathrm{C} / \mathrm{C})$. Compared with the $\mathrm{GG}$ homozygous variant or $\mathrm{G}$ allele, $\mathrm{C}$ carriers or $\mathrm{C}$ allele were not shown to be statistically different between the two groups ( $\mathrm{C}$ carriers: $\mathrm{OR}=1.44$; 95\% CI, 0.91-2.23; $\mathrm{C}$ allele: $\mathrm{OR}=1.45 ; 95 \% \mathrm{CI}, 0.92-2.25)$.

Genotype distribution of COX-2-1195G>A and -765G>C between various degrees of relationship. As shown in Table III, the genotype distribution of $C O X-2-1195 \mathrm{G}>\mathrm{A}$ and $-765 \mathrm{G}>\mathrm{C}$ in different relative grades between the case and control family members was further examined. Since the spouse had no genetic affinity with the host of the family, the spouse was disregarded while analyzing the gastric cancer genetic susceptibility. The OR value of $C O X-2-1195$ AA genotype in the first-degree relatives $(\mathrm{OR}=3.35$; 95\% CI, 1.69-6.12) was higher than that in the seconddegree relatives $(\mathrm{OR}=2.66 ; 95 \% \mathrm{CI}, 1.06-6.82)$. Similarly, the OR values of A carriers (GA + AA) and A allele exhibited a diminished trend from closer degrees of relationship (A carriers: first-degree relatives: OR=2.11; 95\% CI, 1.193.67; second-degree relatives: $\mathrm{OR}=1.98 ; 95 \% \mathrm{CI}, 0.89-4.63$; A allele: first-degree relatives: $\mathrm{OR}=1.77 ; 95 \% \mathrm{CI}, 1.29-2.41$; second-degree relatives: $\mathrm{OR}=1.69 ; 95 \% \mathrm{CI}, 0.99-2.68$ ). Compared with the GG genotype, the mutant genotype distribution of $-765 \mathrm{G}>\mathrm{C}$ was not correlated with gastric cancer in the first- or second-degree relatives, due to the fact that the OR values included 1.00 (C carriers: first-degree relatives: $\mathrm{OR}=1.62$; $95 \% \mathrm{CI}, 0.89-2.87$; second-degree relatives: $\mathrm{OR}=1.35 ; 95 \% \mathrm{CI}, 0.54-3.22$ ).

The interaction of COX-2-1195G $>A$ polymorphism and H. pylori infection status. As COX-2-1195G $>\mathrm{A}$ and $H$. pylori were involved in gastric cancer, the interaction between this functional SNP and H. pylori infection status was examined 
Table II. Genotype distribution of $C O X-2-1195 \mathrm{G}>\mathrm{A}$ and $-765 \mathrm{G}>\mathrm{C}$ in case and control family groups.

\begin{tabular}{|c|c|c|c|}
\hline Locus genotype & $\begin{array}{c}\text { Case family group } \\
\qquad \begin{array}{c}(\%) \\
(\mathrm{n}=296)\end{array}\end{array}$ & $\begin{array}{c}\text { Control family group } \\
\qquad \begin{array}{c}(\%) \\
(\mathrm{n}=319)\end{array}\end{array}$ & OR $(95 \% \mathrm{CI})$ \\
\hline \multicolumn{4}{|l|}{$C O X-2-1195$} \\
\hline $\mathrm{G} / \mathrm{G}$ & 53 (17.9) & $80(25.1)$ & 1.0 \\
\hline $\mathrm{G} / \mathrm{A}$ & $145(49.0)$ & $166(52.0)$ & $1.32(0.86-2.01)$ \\
\hline $\mathrm{A} / \mathrm{A}$ & $98(33.1)$ & 73 (22.9) & $2.03(1.27-3.22)^{\mathrm{a}}$ \\
\hline A carriers & $243(82.1)$ & $239(74.9)$ & $1.55(1.02-2.28)^{\mathrm{a}}$ \\
\hline $\mathrm{G}$ allele & $251(42.4)$ & $326(51.1)$ & 1.0 \\
\hline A allele & $341(57.6)$ & 312 (48.9) & $1.42(1.09-1.81)^{\mathrm{a}}$ \\
\hline \multicolumn{4}{|l|}{$C O X-2-765$} \\
\hline $\mathrm{G} / \mathrm{G}$ & $241(81.4)$ & $275(86.2)$ & 1.0 \\
\hline $\mathrm{G} / \mathrm{C}$ & $53(17.9)$ & $43(13.5)$ & $1.41(0.91-2.20)$ \\
\hline $\mathrm{C} / \mathrm{C}$ & $2(0.70)$ & $1(0.30)$ & $2.28(0.20-25.38)$ \\
\hline $\mathrm{C}$ carriers & 55 (18.6) & $44(13.8)$ & $1.44(0.91-2.23)$ \\
\hline $\mathrm{G}$ allele & $535(90.4)$ & $593(92.9)$ & 1.0 \\
\hline $\mathrm{C}$ allele & $57(9.60)$ & $45(7.10)$ & $1.45(0.92-2.25)$ \\
\hline
\end{tabular}

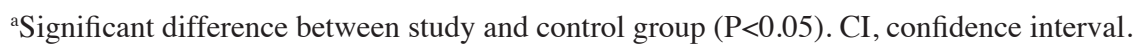

Table III. Genotype distribution of COX-2-1195G $>\mathrm{A}$ and $-765 \mathrm{G}>\mathrm{C}$ between various degrees of relationship (disregarding spouse).

\begin{tabular}{|c|c|c|c|c|c|c|}
\hline \multirow[b]{2}{*}{ Genotype } & \multicolumn{2}{|c|}{ First-degree relatives } & \multirow[b]{2}{*}{ OR $(95 \% \mathrm{CI})$} & \multicolumn{2}{|c|}{ Second-degree relatives } & \multirow[b]{2}{*}{ OR $(95 \% \mathrm{CI})$} \\
\hline & $\begin{array}{l}\text { Case families } \\
\qquad(\mathrm{n}=173)\end{array}$ & $\begin{array}{l}\text { Control families } \\
\qquad(\mathrm{n}=190)\end{array}$ & & $\begin{array}{l}\text { Cases families } \\
\qquad(\mathrm{n}=71)\end{array}$ & $\begin{array}{l}\text { Control families } \\
\qquad(\mathrm{n}=77)\end{array}$ & \\
\hline \multicolumn{7}{|l|}{$C O X-2-1195$} \\
\hline $\mathrm{G} / \mathrm{G}$ & $24(13.9)$ & $48(25.3)$ & 1.0 & $10(14.1)$ & $19(24.7)$ & 1.0 \\
\hline $\mathrm{G} / \mathrm{A}$ & $84(48.6)$ & $102(53.7)$ & $1.66(0.91-3.01)$ & $30(42.3)$ & $36(46.8)$ & $1.58(0.65-3.87)$ \\
\hline $\mathrm{A} / \mathrm{A}$ & $65(37.6)$ & $40(21.1)$ & $3.35(1.69-6.12)^{\mathrm{a}}$ & $31(43.7)$ & $22(28.6)$ & $2.66(1.06-6.82)^{\mathrm{a}}$ \\
\hline A carriers & $149(86.1)$ & $142(74.7)$ & $2.11(1.19-3.67)^{\mathrm{a}}$ & $61(85.9)$ & $58(75.3)$ & $1.98(0.89-4.63)$ \\
\hline $\mathrm{G}$ allele & $132(38.2)$ & $198(52.1)$ & 1.0 & $50(35.2)$ & $74(48.1)$ & 1.0 \\
\hline A allele & $214(61.8)$ & $182(47.9)$ & $1.77(1.29-2.41)^{\mathrm{a}}$ & $92(64.8)$ & $80(51.9)$ & $1.69(0.99-2.68)$ \\
\hline \multicolumn{7}{|l|}{$C O X-2-765$} \\
\hline $\mathrm{G} / \mathrm{G}$ & $139(80.3)$ & $165(86.8)$ & 1.0 & $58(81.7)$ & $66(85.7)$ & 1.0 \\
\hline C carriers & $34(19.7)$ & $25(13.2)$ & $1.62(0.89-2.87)$ & $13(18.3)$ & $11(14.3)$ & $1.35(0.54-3.22)$ \\
\hline
\end{tabular}

${ }^{a}$ Significant difference between study and control group $(\mathrm{P}<0.05)$. CI, confidence interval.

using stratified analysis (Table IV). Taking H. pylori-seronegative AA genotype and A carriers together as a reference, $H$. pylori-seropositive COX-2-1195 AA genotype and A carriers exhibited significantly increased susceptibility to gastric cancer (AA genotype: $\mathrm{OR}=2.96$; 95\% CI, 1.57-5.58; A carriers: $\mathrm{OR}=2.04 ; 95 \% \mathrm{CI}, 1.18-3.52)$.

\section{Discussion}

On the basis of genotyping 296 gastric cancer case family members and 319 control family members in the Chinese Han population, the $C O X-2-1195 \mathrm{AA}$ genotype was found to be associated with an increased risk of gastric cancer $(\mathrm{OR}=2.03$;
95\% CI, 1.27-3.22). The results from our study were consistent with those obtained by Tan et al, Shi et al and Coskunpinar et al (16-18), which indicated that the COX-2-1195AA genotype was associated with advanced colorectal cancer, asthma and lung carcinoma, respectively. However, Peters et al (19) reported that there was no significant difference in the genotype distribution of $C O X-2-1195 \mathrm{~A}>\mathrm{G}$ polymorphism between patients and controls in the risk of head and neck cancer in Caucasian individuals. We have traced the various factors contributing to the contradictory results and found that there were two major reasons for this inconsistency. One reason is that the subjects used in the above studies were selected from different cancer categories. Another reason may be that the 
Table IV. The interaction of $C O X-2-1195 \mathrm{G}>\mathrm{A}$ polymorphism and $H$. pylori infection status.

\begin{tabular}{lcccc}
\hline H. pylori status & Genotype & $\begin{array}{c}\text { Case family } \\
\text { group }(\mathrm{n}=296) \\
(\%)\end{array}$ & $\begin{array}{c}\text { Control family } \\
\text { group }(\mathrm{n}=319) \\
(\%)\end{array}$ & OR (95\% CI) \\
\hline \multirow{3}{*}{ Negative } & COX-2-1195 & & & \\
& GG & $29(9.8)$ & $39(12.2)$ & 1.0 \\
& GA & $26(8.8)$ & $48(15.0)$ & $0.73(0.37-1.43)$ \\
Positive & AA & $27(9.1)$ & $32(10.0)$ & $1.14(0.56-2.29)$ \\
& A carriers & $53(17.9)$ & $80(25.1)$ & $0.89(0.49-1.61)$ \\
& GG & $24(8.10)$ & $41(12.9)$ & 1.0 \\
& GA & $119(40.2)$ & $118(37.0)$ & $1.72(0.98-3.03)$ \\
& AA & $71(24.0)$ & $41(12.9)$ & $2.96(1.57-5.58)^{\mathrm{a}}$ \\
& A carriers & $190(64.2)$ & $159(49.8)$ & $2.04(1.18-3.52)^{\mathrm{a}}$ \\
\hline
\end{tabular}

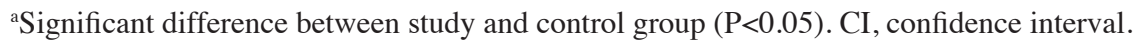

frequency of the $C O X-2-1195$ genotype varies between populations. Our comparative study of the genotype distribution of COX-2-1195 polymorphism has demonstrated the clear differences between the Chinese and Caucasian populations. Frequencies of 25.1, 52.0 and $22.9 \%$ for $1195 \mathrm{GG}, 1195 \mathrm{GA}$, and 1195AA genotypes were found in the Chinese control group, whereas corresponding frequencies of 3, 37 and $59 \%$ were found in Caucasian controls.

Another finding of note in the present study is that the COX-2-1195 AA genotype exhibited a positive correlation with the risk of gastric cancer, and the OR value in the first-degree relatives was higher than that in the second (firstdegree relatives $\mathrm{OR}=3.35$; 95\% CI, 1.69-6.12; second-degree relatives: $\mathrm{OR}=2.66 ; 95 \% \mathrm{CI}, 1.06-6.82)$. It has been proposed that gastric cancer has a familial genetic tendency, and the risk may be reduced according to the decreasing degree of relationship. These results have demonstrated that polymorphisms may play a significant role in the development of gastric cancer. The $C O X-2-1195$ A carriers and A allele exhibit similar trends. However, the OR value of the second-degree relatives had no statistical significance.

The $C O X-2-765 \mathrm{G} / \mathrm{C}$ change appears to be functionally relevant. However, $C O X-2-765 \mathrm{G}>/ \mathrm{C}$ polymorphism failed to exhibit an association with gastric cancer in this study, and there was no significant correlation between the first- and second-degree relatives and $C O X-2-765$ genotypes. This result is consistent with that of Liu et al (13) but differs from findings of studies performed in the populations of The Netherlands and India $(14,15)$. In a study by Sitarz et al, $C O X-2-765 \mathrm{G}$ allele promoter polymorphism was found to be significantly associated with gastric cancer in The Netherlands (14). However, Saxena et al (15) reported that the frequency of the $\mathrm{C}$ carrier has a significant association with gastric adenocarcinoma. This inconsistent result may be due to the markedly different allele frequencies of $C O X-2-765 \mathrm{G} / \mathrm{C}$. The frequencies of the $\mathrm{GG}, \mathrm{GC}$ and $\mathrm{CC}$ genotypes of $C O X-2-765 \mathrm{G} / \mathrm{C}$ were $25.1,52.0$ and $22.9 \%$, respectively, in the present study, whereas Sitarz et al (14) reported the frequencies to be 59, 32 and 9\%, respectively, in The Netherlands. In the study by Saxena et al (15), the Indian and Chinese distributions of $765 \mathrm{GG}, 765 \mathrm{GC}$ and
765CC genotypes were 71.0 versus $86.2 \%, 25.7$ versus $13.5 \%$ and 3.3 versus $0.3 \%$, respectively. Differences in dietary habits or environmental factors (smoking or consumption of alcohol) may be another explanation for these observations. Studies are required to examine the effect of $C O X-2-765 \mathrm{G}>\mathrm{C}$ polymorphism on gastric cancer among various ethnic backgrounds.

H. pylori infection and polymorphism are regarded as major pathogenic factors in gastric cancer development (2). Interaction of $C O X-2-1195 \mathrm{G}>\mathrm{A}$ and $H$. pylori infection status between the case and control family groups was also examined by stratification analysis. As a result, H. pyloriseropositive $C O X-2-1195 \mathrm{AA}$ homozygote and A carriers may exhibit increased susceptibility to gastric cancer (AA homozygote: $\mathrm{OR}=2.96$; 95\% CI, 1.57-5.58; A carriers: $\mathrm{OR}=2.04$; 95\% CI, 1.18-3.52). This indicates that $H$. pylori infection and polymorphism may have a synergistic effect. $H$. pylori infection-induced the $C O X-2$ expression has been previously well evaluated in gastric mucosa (20). H. pylori infection induces up-regulated activation of inflammatory cytokines, which may lead to further alteration of $C O X-2$ expression $(21,22)$. The bacterial virulence factors located outside the $H$. pylori cag Pathogenicity Island (cagPAI) activate MEK/ERK1/-2 signaling to mediate bacterial effects on the $C O X-2$ promoter, an effect that has also been observed in vitro (23). The abovementioned description may facilitate an explanation for the manner in which $H$. pylori infection and $C O X-2-1195 \mathrm{G}>\mathrm{A}$ polymorphism have a combined effect on gastric cancer. However, the exact mechanism underlying the development of gastric cancer remains to be investigated.

In conclusion, this study has demonstrated that the $C O X-2-$ 1195AA genotype is a genetic susceptibility factor of gastric cancer in various degrees of relationship in the Chinese Han population. H. pylori infection may enhance the risk of gastric cancer in individuals with the COX-2-1195AA genotype. Further epidemiologic studies are required to determine the interaction between pro-inflammatory genotypes, dietary habits and exposure to environmental carcinogens. 


\section{Acknowledgements}

This study was supported by grants from National Natural Science Foundation of China (No. 30972547). We thank staff members in Xin'an and Xinxiang County Health Bureau and CDC for their support to our epidemiological study.

\section{References}

1. Hussain SK, Mu LN, Cai L, et al: Genetic variation in immune regulation and DNA repair pathways and stomach cancer in China. Cancer Epidemiol Biomarkers Prev 18: 2304-2309, 2009.

2. Li C, Xia HH, Xie W, et al: Association between interleukin-1 gene polymorphisms and Helicobacter pylori infection in gastric carcinogenesis in a Chinese population. J Gastroenterol Hepatol 2: 234-239, 2007.

3. Correa P: New strategies for the prevention of gastric cancer: Helicobacter pylori and genetic susceptibility. J Surg Oncol 90: 134-138, 2005 .

4. Peek RM Jr and Blaser MJ: Helicobacter pylori and gastrointestinal tract adenocarcinomas. Nat Rev Cancer 2: 28-37, 2002.

5. Macarthur M, Hold GL and El-Omar EM: Inflammation and Cancer II. Role of chronic inflammation and cytokine gene polymorphisms in the pathogenesis of gastrointestinal malignancy. Am J Physiol Gastrointest Liver Physiol 286: 515-520, 2004.

6. Rosenstiel P, Hellmig S, Hampe J, et al: Influence of polymorphisms in the NOD1/CARD4 and NOD2/CARD15 genes on the clinical outcome of Helicobacter pylori infection. Cellular Microbiology 8: 1188-1198, 2006.

7. Hold GL, Rabkin CS, Chow WH, et al: A functional polymorphism of toll-like receptor 4 gene increases risk of gastric carcinoma and its precursors. Gastroenterology 132: 905-912, 2007.

8. Simmons DL, Botting RM and Hla T: Cyclooxygenase isozymes: the biology of prostaglandin synthesis and inhibition. Pharmacol Rev 56: 387-437, 2004.

9. Sun WH, Yu Q, Shen H, et al: Roles of Helicobacter pylori infection and cyclooxygennase-2 expression in gastric carcinogenesis. World J Gastroenterol 10: 2809-2813, 2004.

10. Mrena J, Wiksten JP, Kokkola A, Nordling S, Ristimäki A and Haglund C: $C O X-2$ is associated with proliferation and apoptosis markers and serves as an independent prognostic factor in gastric cancer. Tumor Biol 31: 1-7, 2010.

11. Zhang X, Miao X, Tan W, et al: Identification of functional genetic variants in cyclooxygenase- 2 and their association with risk of esophageal cancer. Gastroenterology 129: 565-76, 2005.
12. Szczeklik W, Sanak M and Szczeklik A: Functional effects and gender association of $C O X-2$ gene polymorphism $\mathrm{G}_{-765} \mathrm{C}$ in bronchial asthma. J Allergy Clin Immunol 114: 248-253, 2004.

13. Liu F, Pan K, Zhang X, et al: Genetic variants in cyclooxygenase-2: expression and risk of gastric cancer and its precursors in a Chinese population. Gastroenterology 130: 1975-1984, 2006.

14. Sitarz R, Leguit RJ, de Leng WW, et al: The $C O X-2$ promoter polymorphism $-765 \mathrm{G}>\mathrm{C}$ is associated with early-onset, conventional and stump gastric cancers. Modern Pathology 21: 685-690, 2008.

15. Saxena A, Prasad KN, Ghoshal UC, Bhagat MR, Krishnani N and Husain $\mathrm{N}$ : Polymorphism of $-765 \mathrm{G}>\mathrm{C} C O X-2$ is a risk factor for gastric adenocarcinoma and peptic ulcer disease in addition to H. pylori infection: a study from northern India. World $\mathrm{J}$ Gastroenterol 14: 1498-1503, 2008.

16. Tan W, Wu J, Zhang X, et al: Associations of functional polymorphisms in cyclooxygenase-2 and platelet 12-lipoxygenase with risk of occurrence and advanced disease status of colorectal cancer. Carcinogenesis 28: 1197-1201, 2007.

17. Shi J, Misso NL, Kedda MA, et al: Cyclooxygenase-2 gene polymorphisms in an Australian population: association of the $-1195 \mathrm{G}>\mathrm{A}$ promoter polymorphism with mild asthma. Clin Exp Allergy 38: 913-920, 2008.

18. Coskunpinar E, Eraltan IY, Turna A and Agachan B: Cyclooxygenase- 2 gene and lung carcinoma risk. Med Oncol doi: $10.1007 / \mathrm{s} 12032-010-9627-8,2010$.

19. Peters WH, Lacko M, te Morsche RH, Voogd AC, Oude Ophuis MB and Manni JJ: COX-2 polymorphisms and the risk for head and neck cancer in white patients. Head Neck 31: 938-943, 2009.

20. McCarthy CJ, Crofford LJ, Greenson J and Scheiman JM: Cyclooxygenase-2 expression in gastric antral mucosa before and after eradication of Helicobacter pylori infection. Am J Gastroenterol 94: 1218-1223, 1999.

21. Kim SS, Ruiz VE, Carroll JD and Moss SF. Helicobacter pylori in the pathogenesis of gastric cancer and gastric lymphoma. Cancer Lett doi:10.1016/j.canlet 2010.07.014, 2011

22. Di JM, Pang J, Sun QP, et al: Toll-like receptor 9 agonists up-regulates the expression of cyclooxygenase-2 via activation of NF-kappaB in prostate cancer cells. Mol Biol Rep 37: 1849-1855, 2010.

23. Jüttner S, Cramer T, Wessler S, et al: Helicobacter pylori stimulates host cyclooxygenase-2 gene transcription: critical importance of MEK/ERK-dependent activation of USF1/-2 and CREB transcription factors. Cell Microbiol 5: 821-834, 2003. 